\title{
Current Indications and Outcome of Pulmonary Resections for Tuberculosis Complications in Ibadan, Nigeria
}

\author{
Mudasiru A. Salami ${ }^{a}$ Arinola A. Sanusi ${ }^{b}$ Victor O. Adegboye ${ }^{a}$ \\ a Division of Cardiothoracic and Vascular Surgery, Department of Surgery and ${ }^{\mathrm{b}}$ Department of Anaesthesia, \\ University College Hospital, College of Medicine, University of Ibadan, Ibadan, Nigeria
}

\section{Significance of the Study}

- In this study the factors for a good outcome in patients presenting with massive or recurrent haemoptysis from tuberculosis (TB) complications were initial stabilization and multidisciplinary care. Hence, improved awareness of high-standard care to encourage inclusion of patients with TB complications in the surgical care protocol as part of national control programmes is recommended.

\section{Keywords}

Pulmonary tuberculosis $\cdot$ Pulmonary resections $\cdot$ Indications for surgery · Haemoptysis · Outcome

\begin{abstract}
Objectives: To review the current indications and outcome of pulmonary resections for tuberculosis (TB) at the Cardiothoracic Surgery Unit of the University College Hospital, Ibadan, Nigeria. Subjects and Methods: A retrospective case series review of patients who had lung resections from January 2014 to January 2017 was performed. Data obtained from medical records included demographics, presenting symptoms, indication for surgery, preoperative evaluation and preparation, operative procedure, postoperative complications, and follow-up. The presence of TB in the patients was confirmed by detecting pathological changes suggestive of TB and/or past history of pulmonary TB associated with its anatomical complications such as cavitation and bronchiectasis. Data were analysed using descriptive statistics. Results: Ten patients had pulmonary resections during
\end{abstract}

\section{KARGER}

E-Mail karger@karger.com www.karger.com/mpp

\section{The Author(s) \\ Published by S. Karger AG, Basel Karger
Open access}

This is an Open Access article licensed under the Creative Commons Attribution-NonCommercial-4.0 International License (CC BY-NC) (http://www.karger.com/Services/OpenAccessLicense), applicable to the online version of the article only. Usage and distribution for commercial purposes requires written permission. this study period. The median age was 33.5 years (range: 3-50). The indication for lung resection was massive or persistent haemoptysis, and 2 patients also had aspergilloma. Six patients (60\%) had lobectomy, 1 had a bilobectomy, and the remaining 3 had pneumonectomy. Complications included partial wound dehiscence in 2 patients, 1 of whom also had postoperative empyema thoracis. One patient died immediately due to haemorrhage. Follow-up ranged from 6 to 37 months. Conclusion: This study showed that the factors for a good outcome in patients presenting with massive or recurrent haemoptysis from TB complications were initial stabilization and multidisciplinary care. Hence, improved awareness of high-standard care to encourage inclusion of patients with TB complications in the surgical care protocol as part of national control programmes is recommended.

(C) 2017 The Author(s)

Published by S. Karger AG, Basel

This paper was presented at the Nigerian Thoracic Society Annual General and Scientific Meeting in Ibadan on November 25, 2016.
Dr. Mudasiru A. Salami

Department of Surgery, University College Hospital, College of Medicine University of Ibadan, PO Box 29225, Secretariat Post Office Ibadan 200212 (Nigeria)

E-Mail mudasiruresearch@gmail.com 


\section{Introduction}

Tuberculosis (TB) remains a leading cause of global morbidity despite the availability of specific chemotherapy for more than 6 decades [1]. In the 2015 World Health Organization (WHO) global report, Nigeria was ranked 5th among countries with the highest burden of the disease [2]. Every year, approximately 245,000 Nigerians die of TB (10\% of all deaths) and about 590,000 new cases occur (of which approx. 140,000 are also HIV positive) [3]. Although surgery for TB was one of the first set of procedures that helped to establish thoracic surgery as a specialty, medical treatment is currently the standard therapy for pulmonary TB [1]. Following the advent of effective chemotherapy in the 1950s, surgical resection of the affected lung, which used to be the treatment of choice, faded into the background [4]. However, currently, lung resection is increasingly used to treat complications of pulmonary TB and multidrug-resistant TB (MDRTB) [4, 5]. Complications of TB amenable to surgical resection of the lung include massive haemoptysis, bronchiectasis, bronchial stenosis, bronchopleural fistula, and aspergilloma [5].

The current WHO expert recommendation suggests that surgical resection requires a team of specialists and facilities as well as a centre of excellence in order to provide the required level of care throughout the process (before, during, and after surgery) [6]. Such a centre should be well equipped and well staffed with modern preoperative investigations, operating theatres, and efficient postoperative care units because of the associated high perioperative morbidity and mortality [6-8]. This is partly due to the need for a multidisciplinary approach when a patient is being considered for surgery, with the decision expected to be made together by physicians, surgeons, anaesthesiologists, physiotherapists, and other specialists. This approach helps to limit complications and ensure an acceptable outcome following surgery. There is a paucity of such centres in Nigeria offering high-level surgery which is also evident in limited reports on the subject in the literature [9]. Thus, the current complication, mortality, and morbidity rates of such procedures remain unknown in Nigeria. Hence, the objective of this study was to review our recent experience in the surgical treatment of TB in the last 3 years at the Cardiothoracic Surgery Unit of a tertiary hospital: University College Hospital, Ibadan, Nigeria.

\section{Subjects and Methods}

All cases of referral patients suffering from pulmonary TB or its complications who had undergone lung resections in the Cardiothoracic Surgery Unit, University College Hospital, Ibadan, Nigeria from January 2014 to January 2017 were reviewed. The medical records of the patients including case files, operational summaries, and special proforma that were designed in the unit were used to maintain a continuously updated database. Data obtained from the medical records of each patient included demographics (age at surgery, sex), presenting symptoms, indication for surgery, preoperative work-up including imaging, intraoperative events, postoperative complications, recovery, and follow-up. The presence of TB in the patients was confirmed by identifying the microorganism in the tissues, detecting pathological changes suggestive of TB, and/or having past history of pulmonary TB associated with its anatomical complications such as cavitation, bronchiectasis, and caseous necrosis. The study was performed according to the principles of the Helsinki Declaration and approved by the University of Ibadan/University College Hospital, Ibadan Ethics Committee as part of an outcome audit of all procedures done in the unit.

\section{Perioperative Care/Surgical Technique}

All the patients were admitted in the stable phase of the disease (with no active haemoptysis) except one who had to have surgery on a semi-emergent basis. They all had preoperative pulmonary function tests (except the 3-year-old patient, for whom pulmonary function tests were not feasible), with a minimum criterion of forced expiratory volume in $1 \mathrm{~s}$ greater than $1.5 \mathrm{~L}$ in cases of lobectomy and greater than $2.0 \mathrm{~L}$ where pneumonectomy was planned. Electrocardiogram and echocardiography were done to rule out heart failure and pulmonary hypertension. Pulmonary function tests were not feasible in the 3-year-old patient. The protocol was to commence preoperative chest physiotherapy including breathing exercise 3-5 days before surgery to fully optimize the patients and ensure familiarization with instructions of postoperative physiotherapy. Each patient except the 3-year-old had general anaesthesia and was intubated using a double-lumen tube and mechanically ventilated. As there was no appropriate double-lumen tube for the 3-year-old, a standard tracheal tube was passed and advanced into the dependent bronchus to ventilate the normal lung. Tube placement was confirmed by visualization and auscultation. Surgery was done for each case when the disease was sufficiently localized using chest CT to allow surgery, the remaining lung tissue around the resectional margins was estimated to be free of TB, and the patient's surgical risk level was acceptable, with sufficient pulmonary reserve to tolerate the resection.

\section{Statistical Analysis}

Descriptive statistical analysis was performed using frequencies and percentages.

\section{Results}

The characteristics of the 10 patients ( 7 males and 3 females) who had pulmonary resection during the study period are given in Table 1 . The median age was 33.5 years 
Table 1. Characteristics of patients

\begin{tabular}{|c|c|c|c|c|}
\hline Patient & $\begin{array}{l}\text { Age, } \\
\text { years/sex }\end{array}$ & Presentation & $\begin{array}{l}\text { Operation } \\
\text { performed }\end{array}$ & Complications/discharge \\
\hline 1 & $32 / \mathrm{F}$ & $\begin{array}{l}16 \text { years of persistent cough } \\
10 \text { years of recurrent haemoptysis }\end{array}$ & $\begin{array}{l}\text { Left upper } \\
\text { lobectomy }\end{array}$ & $\begin{array}{l}\text { Partial wound dehiscence } \\
\text { Postoperative empyema } \\
\text { Discharged } 2 \text { weeks after operation }\end{array}$ \\
\hline 2 & $21 / \mathrm{F}$ & Massive haemoptysis & $\begin{array}{l}\text { Left upper } \\
\text { lobectomy }\end{array}$ & $\begin{array}{l}\text { None } \\
\text { Discharged } 7 \text { days after operation }\end{array}$ \\
\hline 3 & $45 / \mathrm{M}$ & Massive haemoptysis & $\begin{array}{l}\text { Left upper } \\
\text { lobectomy }\end{array}$ & $\begin{array}{l}\text { None } \\
\text { Discharged } 9 \text { days after operation }\end{array}$ \\
\hline 4 & $37 / \mathrm{M}$ & Massive haemoptysis & $\begin{array}{l}\text { Left upper } \\
\text { lobectomy }\end{array}$ & $\begin{array}{l}\text { None } \\
\text { Discharged } 8 \text { days after operation }\end{array}$ \\
\hline 5 & $50 / \mathrm{M}$ & $\begin{array}{l}\text { Recurrent cough since childhood (10 years) } \\
\text { Recurrent haemoptysis (first episode at age } 10)\end{array}$ & $\begin{array}{l}\text { Right pneumo- } \\
\text { nectomy }\end{array}$ & $\begin{array}{l}\text { Massive postoperative haemorrhagic } \\
\text { shock/died }\end{array}$ \\
\hline 6 & $35 / \mathrm{M}$ & $\begin{array}{l}3 \text { years of recurrent haemoptysis - major } \\
\text { (about } 200 \mathrm{~mL} \text { ) } \\
\text { Previous anti-tuberculosis treatment: } 8 \text { months }\end{array}$ & $\begin{array}{l}\text { Left lower } \\
\text { lobectomy }\end{array}$ & $\begin{array}{l}\text { Wound infection } \\
\text { Discharged } 8 \text { days after operation }\end{array}$ \\
\hline 7 & $40 / \mathrm{M}$ & $\begin{array}{l}10 \text { months of recurrent haemoptysis; massive } \\
\text { chest CT: suggestive of benign mass with air- } \\
\text { crescent mass }\end{array}$ & $\begin{array}{l}\text { Right bilobectomy } \\
\text { (upper and } \\
\text { middle lobes) }\end{array}$ & $\begin{array}{l}\text { Postoperative itraconazole } \\
\text { Discharged } 8 \text { days after operation }\end{array}$ \\
\hline 8 & $21 / \mathrm{M}$ & Recurrent haemoptysis of 1year duration & $\begin{array}{l}\text { Left upper } \\
\text { lobectomy }\end{array}$ & $\begin{array}{l}\text { None } \\
\text { Discharged } 8 \text { days after operation }\end{array}$ \\
\hline 9 & $3 / \mathrm{M}$ & $\begin{array}{l}\text { Cough of } 2 \text { weeks duration } \\
\text { Associated breathlessness and persistent fever } \\
\text { Chest X-ray: a homogenous opacity involving } \\
\text { the right hemithorax } \\
\text { Chest CT scan: well-circumscribed hypodense } \\
\text { lesions in the right upper and middle lung zones; serial } \\
\text { axial slices showed loculations within the lesions }\end{array}$ & $\begin{array}{l}\text { Right pneumo- } \\
\text { nectomy }\end{array}$ & $\begin{array}{l}\text { Histology: granulomatous inflammati- } \\
\text { on probably from tuberculosis } \\
\text { Anti-tuberculous drugs with fever } \\
\text { subsiding after commencement } \\
\text { Discharged } 4 \text { weeks after operation }\end{array}$ \\
\hline 10 & $26 / \mathrm{F}$ & $\begin{array}{l}\text { Known patient with pulmonary tuberculosis treated } \\
16 \text { years previously } \\
\text { Recurrent haemoptysis in the last } 6 \text { years }\end{array}$ & $\begin{array}{l}\text { Right } \\
\text { pneumonectomy }\end{array}$ & $\begin{array}{l}\text { Superficial wound infection } \\
\text { Discharged } 13 \text { days after operation }\end{array}$ \\
\hline
\end{tabular}

(range: $3-50$ ). The main presenting symptom was massive haemoptysis. The chest radiographs of the patients showed the typical intracavitary mass surrounded by a crescent of air ("air-crescent" sign) in 2 cases (patients 1 and 4; both in the upper lobes) with aspergilloma. For patient 1 , the air-crescent sign diagnosed in 2008 (Fig. 1a) persisted in 2015 (Fig. 1b). Other radiographic features included dense apical fibrocalcified lesions, nodular mass, destruction of the lung, and cavitation.

The types of operation performed included lobectomy, bilobectomy, and pneumonectomy, and the approach was posterolateral thoracotomy. Mobilization of the lobe(s) or the entire lung (in the case of pneumonectomy) was done in such a way as to avoid contamination of the pleural space. Six patients $(60 \%)$ had lobectomy, 1 had a bilobectomy, and 3 had pneumonectomy. The postoperative chest radiograph for patient 1 , who had a left upper lobectomy, showed expansion of the residual left lower lobe (Fig. 2). The indications for lung resection were mainly massive or persistent haemoptysis, while 2 patients also had aspergilloma (patients 1 and 4; Table 1). Patient 4, a male, had multiple episodes of haemoptysis while on admission and was initially transfused and managed until he remained stable and haemoptysis free for a week prior to his semi-urgent surgery. Patients 2 and 9 were diagnosed preoperatively as lung sequestration and infected bronchogenic cysts, respectively. However, the intraoperative findings and final histopathology results confirmed pulmonary TB and both were placed on postoperative anti-TB chemotherapy with good outcome. 


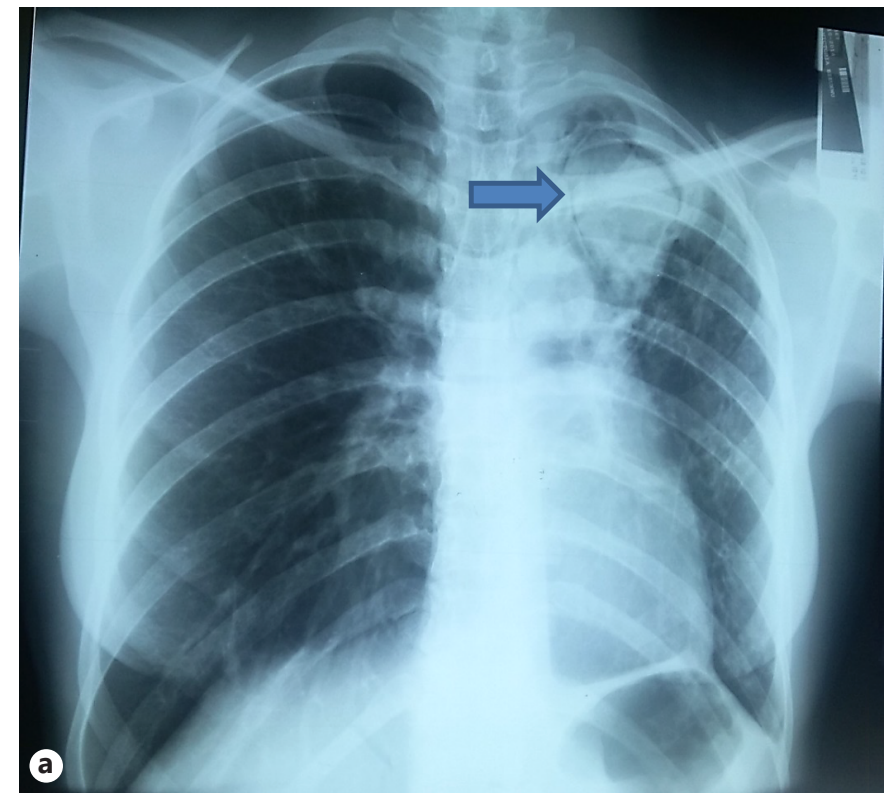

Fig. 1. Chest X-ray of patient 1 done in 2008 showing fungal ball in the apex of the left lung (a) that persisted in 2015 (b).

The remaining patients had been previously treated with chemotherapy prior to surgery. The 2 patients who had aspergilloma were placed on postoperative itraconazole as per the institution's protocol.

Two patients (patients 1 and 10) who had lobectomy developed partial wound dehiscence, 1 of whom also had postoperative empyema thoracis. Both complications resolved on conservative management (honey dressing, adequate drainage, physiotherapy, and appropriate antibiotics). There was an incidence of immediate postoperative mortality due to massive haemorrhage complicated with disseminated intravascular coagulation (patient 5). The patient had a chronic disease spanning 40 years and clearly had unusually extensive vascularized adhesions. All other patients were discharged home on average within 11 days postoperatively. Their regular follow-up in the clinic was without any further complications. The median follow-up was 18 months (range: 6-37).

\section{Discussion}

In this study of patients with $\mathrm{TB}$, pulmonary resection procedures were effective with limited complications. The commonest indication for pulmonary resection was

Pulmonary Resections for Tuberculosis in Nigeria
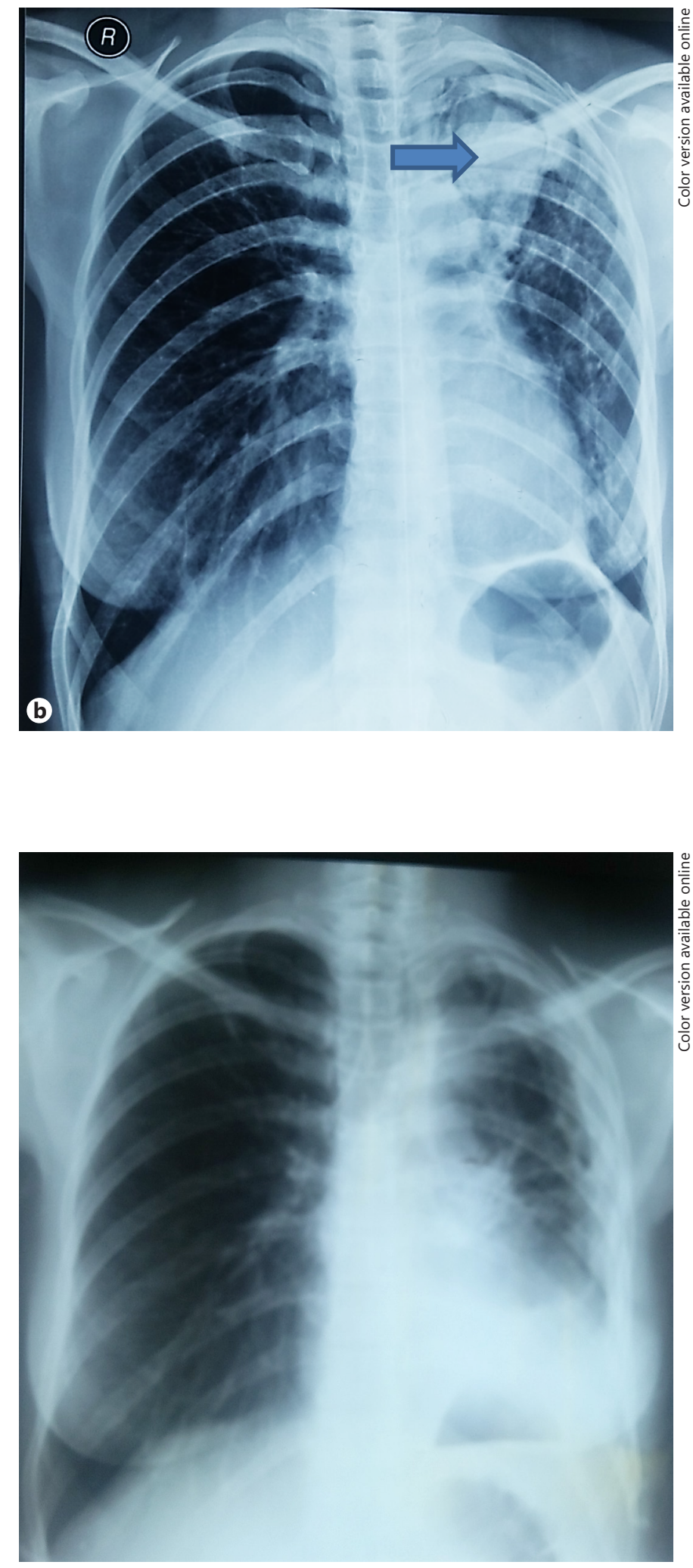

Fig. 2. Postoperative chest $X$-ray of patient 1 showing expansion of the residual left lower lobe with some heterogeneous infiltrate, and an ipsilateral mediastinal shift with subcutaneous emphysema. 
life-threatening massive haemoptysis, as previously reported in patients with massive haemoptysis and cavitary or bronchiectatic disease [10]. The finding that most of the patients were referred after previous anti-TB treatment could indicate a mistaken effort to use chemotherapy to resolve haemoptysis. Equally important, half of the patients were placed on repeat courses of anti-TB therapy even after being converted to sputum-negative status after the first treatment regimen. This observed delay in referral suggests an urgent need for the creation of awareness of a facility with an established protocol to manage such patients. Reports from a recent Turkish study similarly showed $12 \%$ of a cohort of patients with pulmonary TB presenting with haemoptysis. This supports the call for more interaction between cardiothoracic surgeons and pulmonary physicians to identify at an early stage patients who may benefit from surgery [11]. Similar to findings in our series, other authors have also reported haemoptysis as the commonest indication for intervention in patients with $\mathrm{TB}$, although they intervened earlier with emergency surgeries in cases of massive haemoptysis $[5,9,12]$.

In this study, the $10 \%$ mortality rate was similar to $7 \%$ reported previously by Erdogan et al. [10] and 2-8\% reported from Russia [13] after pneumonectomy. We used a double-lumen tube to achieve one-lung ventilation for all our lung resections to improve exposure and protect the contralateral lung from soilage [14]. We placed 2 of our patients on anti-TB therapy in line with postoperative histological diagnosis because the effect of TB is usually beyond the resected lungs $[5,15,16]$.

The predominance of left-sided resection in the present series and other published reports $[3,9]$ indicated that the more horizontal course of the narrower left main bronchus and the smaller peribronchial space contributed to the left lung being more commonly involved. It is notable that none of our patients had pulmonary resections for drug-resistant TB. There is a need for further interaction with the local MDRTB centre for us to jointly identify patients who may benefit from pulmonary resection as a curative option. Further collaboration with the centre in our hospital will be important, as present-day pulmonary resection combined with anti-TB chemotherapy for MDRTB is reported to achieve high treatment success rates (88-95\% of cases) [5, 7, 17-19]. In the case of bilateral lesions, resection is recommended on the side with the greater lesions [6]. The 2 most frequent indications for lung resection in drug-resistant $\mathrm{TB}$ are (i) failed medical treatment with persistent sputum positivity or (ii) patients who have had medical treatment and are sputum negative, but with persistent localized cavitary disease or bronchiectasis which are potential safe havens for mycobacteria bacilli due to difficulty in drug penetration. The tuberculous cavity offers an ideal growth environment as its wall can limit drug penetration and its environment is thought to protect Mycobacterium tuberculosis from host defences [20,21]. We advise a semi-urgent intervention after a haemoptysis-free window period, as ongoing haemoptysis has been reported as a risk factor for bronchopleural fistula and increased mortality [9].

The limitations of this study include the small population, which is due to its being a subset of patients with TB presenting with complications amenable to surgery, and its retrospective design.

\section{Conclusion}

This study showed that the factors for a good outcome in patients presenting with massive or recurrent haemoptysis from TB complications were initial stabilization and multidisciplinary care. Hence, improved awareness of high-standard care to encourage inclusion of patients with TB complications in the surgical care protocol as part of national control programmes is recommended.

\section{References}

1 Evangelopoulos D, da Fonseca JD, Waddell SJ: Understanding anti-tuberculosis drug efficacy: rethinking bacterial populations and how we model them. Int J Infect Dis 2015;32: 76-80.

2 World Health Organization: Global TB Report. 2015. http://apps.who.int/iris/bitstream/ 10665/191102/1/9789241565059_eng.pdf (accessed November 2, 2016).

3 Vassal A: White paper report of Nigeria's Perspective on Tuberculosis - Post-2015 Devel- opment Agenda. Copenhagen Consensus on Sustainable Development Goals. 2015. http:// www.copenhagenconsensus.com/sites/default/files/nigeria_tb_resource_packet_0.pdf (accessed November 1, 2016).

4 Kempker RR, Vashakidze S, Solomonia N, et al: Surgical treatment of drug-resistant tuberculosis. Lancet Infect Dis 2012;12:157-166.

5 Madansein R, Parida S, Padayatchi N, et al: Surgical treatment of complications of pulmonary tuberculosis, including drug-resis- tant tuberculosis. Int J Infect Dis 2015;32:6167.

6 World Health Organization: The role of surgery in the treatment of pulmonary TB and multidrug- and extensively drug-resistant TB. 2014. http://www.euro.who.int/_data/assets/pdf_file/0005/259691/The-role-of-surgery-in-the-treatment-of-pulmonary-TBand-multidrug-and-extensively-drug-resistant-TB.pdf?ua $=1$ (accessed November 2, 2016). 
7 Dewan RK: Surgery for pulmonary tuberculosis - a 15-year experience. Eur J Cardiothorac Surg 2010;37:473-477.

8 Man MA, Nicolau D: Surgical treatment to increase the success rate of multidrug-resistant tuberculosis. Eur J Cardiothorac Surg 2012; 42:e9-e12.

9 Adebonojo SA, Adebo OA, Osinowo O, et al: Management of tuberculosis destroyed lung in Nigeria. J Natl Med Assoc 1981;73:39-42.

10 Erdogan A, Yegin A, Gürses G, et al: Surgical management of tuberculosis-related hemoptysis. Ann Thorac Surg 2005;79:299-302.

11 Guler SA, Bozkus F, Inci MF, et al: Evaluation of pulmonary and extrapulmonary tuberculosis in immunocompetent adults: a retrospective case series analysis. Med Princ Pract 2015;24:75-79.
12 Dezfouli AA, Kakhki AD, Farzanegan R, et al: Results of lobectomy and pneumonectomy in pulmonary TB. Tanaffos 2003;2:33-39.

13 Zaleskis R: Role of surgical methods in the treatment of tuberculosis (in Russian). Probl Tuberk 2001;9:3-5.

14 Campos JH: Current techniques for perioperative lung isolation in adults. Anesthesiology 2002;97:1295-1301.

15 Behr MA, Waters WR: Is tuberculosis a lymphatic disease with a pulmonary portal? Lancet Infect Dis 2014;14:250-255.

16 Dokhan AL, Abd Elaziz ME, Yousif M, et al: Surgical management of hemoptysis in pulmonary tuberculous patients. J Egypt Soc Cardiothorac Surg 2016;24:78-85.

17 Naidoo R, Reddi A: Lung resection for multidrug-resistant tuberculosis. Asian Cardiovasc Thorac Ann 2005;13:172-174.
18 Pontali E, Matteelli A, D’Ambrosio L, et al: Rediscovering high technology from the past: thoracic surgery is back on track for multidrug-resistant tuberculosis. Expert Rev Anti Infect Ther 2012;10:1109-1115.

19 Xu HB, Jiang RH, Li L: Pulmonary resection for patients with multidrug-resistant tuberculosis: systematic review and meta-analysis. J Antimicrob Chemother 2011;66:1687-1695.

20 Kaplan G, Post FA, Moreira AL, et al: Mycobacterium tuberculosis growth at the cavity surface: a microenvironment with failed immunity. Infect Immun 2003;71:7099-8108.

21 Vashakidze S, Despuig A, Gogishvili S, et al: Retrospective study of clinical and lesion characteristics of patients undergoing surgical treatment for pulmonary tuberculosis in Georgia. Int J Infect Dis 2017;56:200-207. 